\title{
LA LÍRICA DE ARJONA Y AGOSÍN SOBRE FEMINICIDIOS EN MÉXICO
}

\author{
A LIIRICA DE ARJONA E AGOSÍN SOBRE \\ FEMINICÍDIOS NO MÉXICO
}

\section{ARJONA AND AGOSÍN'S LYRICS ABOUT FEMINICIDE IN MEXICO}

\author{
Carlos Magno Gomes ${ }^{1}$ \\ [http://orcid.org/0000-0001-9070-9010] \\ DOI: 10.30612/raido.v15i38.14877
}

\begin{abstract}
RESUMEN: Este artículo analiza las estrategias líricas de la reproducción de la voz de las víctimas de feminicidios en Ciudad Juárez, en México, a partir de la poesía de Arminé Arjona y Marjorie Agosín, que prestan un homenaje a las silenciadas mientras reproducen performances feministas contra la impunidad de los crímenes. Debatimos las especificidades del activismo lírico y sus estrategias para dar voz a las mujeres torturadas por medio de secuestros, violaciones y mutilaciones que culminan con el feminicidio. Metodológicamente, articulamos conceptos de performance lírica, según Paul Zumthor, y de activismo feminista, propuesto por Julia Fragoso y Rita Segato, para indicar las intersecciones entre la voz lírica y el clamor de la mujer ejecutada.
\end{abstract}

Palavras-chave: Performance lírica; lucha contra el feminicidio; poesía de resistencia.

RESUMO: Este artigo analisa as estratégias líricas da reproduçâo da voz das vítimas de feminicídios em Ciudad Juárez, no México, a partir da poesia de Arminé Arjona e Marjorie Agosín, que prestam homenagem às silenciadas enquanto produzem performances feministas contra a impunidade dos crimes. Debatemos as especificidades do ativismo lírico e suas estratégias para dar voz às mulheres torturadas por meio de sequestros, violaçōes e mutilaçōes que culminam com o feminicídio. Metodologicamente, articulamos conceitos de performance lírica, segundo Paul Zumthor, e de ativismo feminista, proposto por Julia Fragoso e Rita Segato, para identificarmos as intersecçōes entre a voz lírica e o clamor da mulher executada.

Palavras-chave: Performance lírica; luta contra o feminicídio; poesia de resistência.

ABSTRACT: This article analyses the lyrical strategies of voice reproduction of victims of feminicide in Ciudad Juárez, Mexico, based on the poetry of Arminé Arjona and Marjorie

1 Prof. de Teoría Literaria (UFS/CNPq), doctor en Literatura por la UnB (2004) con postdoctorado en Estudios Literarios por la UFMG (2013). Miembro del GT de la Anpoll: "La mujer en la literatura". Editor del periódico Interdisciplinar.Contacto: calmag@bol.com.br 
Agosín, who pay homage to the silenced while producing feminist performances against the impunity of crimes. We debate the specificities of lyrical activism and its procedures to give voice to women tortured through kidnapping, rape, and mutilation that culminate in feminicide. Methodologically, we articulate concepts of lyrical performance, according to Paul Zumthor, and feminist activism, proposed by Julia Fragoso and Rita Segato, to identify the intersections between the lyrical voice and the clamour of these executed women.

Keywords: Lyrical performance; fight against feminicide; poetry of resistance.

\section{PRECEDENTES LÍRICOS}

Entre la última década del siglo XX y las primeras del XXI, millones de mujeres fueron víctimas de feminicidios en la Ciudad Juárez, en la frontera entre México y Estados Unidos. No hay una causa específica, diversos factores contribuyeron a la impunidad de estos crímenes, que son fruto de abismos económicos y sociales y de valores morales patriarcales. En el inicio de estos crímenes, el norte de México era asolado por la violencia del narcotráfico y por la corrupción que corroía el debate político por políticas públicas. La mayoría de las víctimas eran trabajadoras, con bajos salarios, de industrias extranjeras, las llamadas "empresas maquilladoras", que se instalaron en aquella región a partir de acuerdos entre los países que forman el NAFTA: Estados Unidos, Canadá y México. Tales feminicidios fueron menospreciados por las autoridades y por la falta de investigación adecuada, y durante años fueron silenciados y olvidados por un Estado omiso.

En la lucha por la justicia, diferentes movimientos feministas iniciaron campañas de reivindicación por los derechos de las víctimas y pasaron a gritar por justicia y punición para los culpables. Para la antropóloga Marcela Lagarde, una de las principales voces de esta lucha, "el feminicidio es una ínfima parte visible de la violencia contra niñas y mujeres, sucede como culminación de una situación caracterizada por la violación reiterada y sistemática de los derechos humanos de las mujeres" (2005, p.01). Contra la onda de crímenes impunes, además de las académicas, diversas poetas pasaron a producir textos que se proyectaron como performances artísticas que clamaban por justicia, mientras que rendían homenajes a la memoria de las silenciadas.

En este contexto, consideramos a la poesía sobre feminicidios como una performance feminista. Este activismo nos estimula a repasar las partituras de cada texto producido con el propósito de denunciar los trágicos acontecimientos. En común, tal poesía retoma el grito de justicia y se proyecta contra la cultura misógina que está por tras de estos crímenes. Para este artículo, vamos a analizar la producción de la chilena-americana Marjorie Agosín y de la mexicana Arminé Arjona, que presentan puntos en común en sus estrategias líricas acerca de los feminicidios. Las dos contextualizan los crímenes y tienen en cuenta las peculiaridades políticas y geográficas de Ciudad Juárez, que vio su desierto ser usado como un pantano de cuerpos cercenados y mutilados por violentos estupros seguidos de muerte.

Cabe observar que el término feminicidio es amplio, pero tiene como punto convergente la tipicidad del crimen contra la mujer por esta ser mujer, es decir, específcamente, por su condición de género. Usamos este concepto como "una herramienta 
crítica que concibe varios factores de estudio y análisis en torno de asesinatos de mujeres en los cuales están presentes los motivos, los victimarios, los actos de violentos, los cambios estructurales en cada sociedad" (FRAGOSO, 2010, p. 247). En Juárez, el feminicidio es el ápice de diferentes crímenes que envuelven secuestros, violaciones, mutilaciones y prostitución de mujeres anónimas. Tales rituales van acompañados de uso desenfrenado de alcohol y drogas, con rituales de tortura y de violaciones sexuales.

Esta violencia descomunal está asociada a la agresividad masculina y al culto de la virilidad propio de aquella región. Cabe destacar que la regulación de las identidades de género y prácticas sexuales son "dependientes de condiciones sociales" y están relacionadas a diferentes tendencias comportamentales vinculadas a la globalización, a la violencia social, a los valores morales e, inclusive, a la forma como la justicia se proyecta en el imaginario popular (CONNELL; PEARSE, 2015, p. 210).

Para sociólogos/as y antropólogos/as, los feminicidios tienen como telón de fondo la pobreza y el machismo ancestral impuesto por la colonización. Segato reconoce que “allí, más que en cualquier otro lugar, se vuelve real el lema 'cuerpo de mujer: peligro de muerte'. Ciudad Juárez es también, significativamente, un lugar emblemático de la globalización económica y del neoliberalismo, con su hambre insaciable de ganancia" (2013, p. 11). Además de este peligro constante, las mujeres son aniquiladas simbólicamente por normas de género "de larga duración del poder masculino como poder patriarcal de controlar y hacer que las mujeres obedezcan" (MACHADO, 2017, p. 42).

A continuación, proponemos algunas reflexiones sobre el activismo lírico que surgió a principios del siglo XXI en Juárez.

\section{DE LA VOZ A LA PERFORMANCE}

Entre tantos colectivos que pasaron a reivindicar los derechos de las mujeres, diferentes grupos producían y divulgaban poesías que resonaban las voces feministas silenciadas. La gravedad de los acontecimientos brutales era cuestionada por diversos intelectuales y artistas. Entre los primeros movimientos colectivos dirigidos a llamar la atención de lo que estaba sucediendo en Juárez, destacamos el proyecto internacional FacingFaces Violencia, basta ya!; las publicaciones de poetas sobre las muertas de Juárez en la revista Metapolítica; los encuentros de poetas que fueron coordinados por Carmen Amato en Ciudad Juárez, entre los años de 2002 y 2003; y la antología editada por Juan Armando Rojas y Jennifer Rathbun: Canto a una ciudad en el desierto de 2004 (AYALA, 2005, p. 106). Tales acontecimientos dieron inicio a una tradición de performances que fueron relevantes en la lucha por los derechos de las mujeres mexicanas ${ }^{2}$.

En la producción lírica de esta primera fase, tres poetas de Ciudad Juárez se destacaron: Arminé Arjona, Susana Chávez y Micaela Solís por estar en la vanguardia del cuestionamiento de la violencia estructural. Ellas fueron más allá del vínculo entre los feminicidios y el narcotráfico, exploraron en sus escrituras la premisa de que estos crímenes eran parte de una violencia estructural contra la mujer. Además de registrar

2 Este artículo trae datos de una investigación que recibe apoyo financiero del CNPq y abarca un análisis comparativo de diferentes formas de representaciones del feminicidio en textos líricos y narrativos de autoría femenina en América Latina. 
particularidades de la desigualdad de género, sus poesías estaban preocupadas en registrar la forma como estos crímenes afectaban a la sociedad mexicana (ROJAS JOO, 2016, p. 53).

Para este artículo, vamos a concentrarnos en las obras de Arminé Arjona y Marjorie Agosín. Por la estrecha relación entre feminismo y activismo, estratégicamente, escribir y leer el texto se mezclan por medio del rescate/homenaje de las voces silenciadas. Para Paul Zumthor, la poesía abarca el soporte vocal, pues incluye diversos aspectos exteriores que interfieren directamente en la comprensión textual y en los nuevos sentidos que el texto va agregando en sus diferentes lecturas, pues "el lugar de la obra se invertiría en los elementos performativos, no textuales, como la persona y el juego del intérprete, el auditorio, las circunstancias, el ambiente cultural y, en profundidad, las relaciones intersubjetivas, las relaciones entre la representación y lo vivido" (ZUMTHOR, 2018, p. 18).

Por la perspectiva de los estudios de género, la poesía de Arjona y Arminé nos ofrece reflexiones sobre cómo se naturaliza la violencia de género en México. Para estas constataciones, articulamos las contribuciones antropológicas de Segato sobre cómo la desigualdad de género apuntala los brutales feminicidios de Juárez, ya que existe una "violencia estructural de género", que es un fenómeno "percibido y asimilado como parte de la 'normalidad' o, lo que sería peor, como un fenómeno 'normativo', es decir, que participaría del conjunto de las reglas que crean y recrean esa normalidad" (2003, p. 132). En este contexto, las estrategias violentas contra la mujer dialogan con las tradiciones machistas que vinculan la violencia a la masculinidad dominante y refuerzan la agresividad como norma, pues, estratégicamente "los nińos suelen hacer movimientos agresivos y reivindican poder" (CONNELL; PEARSE, 2015, p.56).

Así, al leer los poemas de Arjona y Arminé, pretendemos explorar la voz pulsante de sus textos. Sus proyectos de escritura se confunden con la lectura comprometida. Se trata, por lo tanto, de una intersección performativa que también significa convocación para ampliar el horizonte cultural sobre los crímenes de Juárez. Así, nos apropiamos de las tristes experiencias y trayectos de los cuerpos de las mujeres sacrificadas. En esta dinámica, leer es rescatar el murmullo. Es prepararse para oír el sonido del silencio del desierto mexicano, dado que "no hay una recepción textual desconectada de la persona que lee, de la actuación del/de la intérprete, del público, del momento y de los elementos culturales. Por eso, hay una relación directa entre la recepción del texto poético con el cuerpo vivo" (ZUMTHOR, 2018, p. 27).

Por la perspectiva de la performance activista, la poesía de Arjona y Agosín trae reflexiones de cuánto debe ser cuestionado el imaginario del aniquilamiento simbólico de la mujer. Tal tipo de rebajamiento forma parte de una dinámica de la colonización masculina sobre el cuerpo femenino. Para estas normas, el cuerpo sacrificado refuerza el poder masculino de exhibir su brutal forma de imponer reglas sociales, dado que, en una guerra, el exterminio de la víctima puede ser visto como el poder de dominación del agresor, "porque solamente el poder de colonización permite la exhibición del poder de muerte ante los destinados a permanecer vivos" (SEGATO, 2013 p. 20-21).

En el proceso de recepción, entendemos como una performance activista no solo la producción de la poesía sino también el acto de leer. Así, exploramos la decodificación de los diferentes lenguajes estéticos que se entrecruzan en esta producción 
con la fundamentación del concepto de "performance", cuñado por Paul Zumthor. La potencialización de este cuerpo, que se proyecta por medio de la voz lírica de denuncia, fortalece su contenido de confrontación, porque "lo poético tiene de profundo, fundamental necesidad, de ser percibido en su calidad y para generar sus efectos, de la presencia activa de un cuerpo" (ZUMTHOR, 2018, p. 38).

Las performances de estas poesías que pasaron a resonar por México, proyectaron el texto lírico como un espacio de resistencia. Este acontecimiento social envuelve a las diversas instituciones y lugares públicos como mercados, diversas escuelas y plazas públicas: "El evento se acercó a la comunidad y en numerosos casos la mancuerna sociedad y cultura lograron una armoniosa existencia. Con la propuesta de sacar la poesía al espacio público se logró la comunicación social y por lo tanto una expresión artística transparente surgida de la actividad diaria" (ROJAS JO0, 2016, p. 51).

Este activismo nos inspira a releer estos textos, entonando el lamento por medio de gestos y del movimiento corporal, enfatizando cuánto es lamentable la banalización de estas muertes, por eso, creemos que "cada performance nueva coloca todo en cuestión. La forma se percibe como performance, pero en cada performance esta se transmuta" (ZUMTHOR, 2018, p. 36). Por esta perspectiva, el poema actualiza los significados del feminicidio cuando funde el papel de la poeta con el del/la lector/a, viabilizando la proyección del grito colectivo y dando énfasis en el "ahora", como lugar de enunciación y de "conocimiento del oyente-espectador" (ZUMTHOR, 2018, p.69).

A continuación, pasamos a explorar las experiencias estéticas de la poesía de Arjona para sensibilizar el/la lector/a sobre la gravedad de los crímenes, proponiendo el compromiso lírico como cultivo de la memoria de las víctimas.

\section{EL GRITO FEMINISTA}

Al leer la poesía de Arminé Arjona, tenemos la sensación de estar enfrente de un desierto de llantos y gritos. En el poema "El fragor del silencio", hay una réplica de los lamentos de las víctimas: "Voces lerdas, desoladas/fragorosas voces del silencio" (2011). El llanto infinito de estas mujeres nos deja sordos y tristes, pero no podemos dejar de recordarlas, pues necesitamos reforzar cómo la crueldad de este genocidio fue responsable por millones de muertes. En la poesía de Arjona, las voces desoladas vienen entrecortadas por el viento seco del desierto y están exhaustas de llorar. Son víctimas del odio masculino y de la impunidad a pesar de haber sido impedidas de seguir sus sueños.

Al reproducir esta sinfonía de tristes gritos por medio de aliteraciones, Arjona homenajea la voz de todas las silenciadas y reconoce el lamento colectivo: "Voz sin ruido en la voz/y sin descanso vos/la voz ya quieta/Emasculada voz de las tormentas/ atormentada vos y quebrantada" (2011). El juego entre la voz de la ejecutada y el vos atormentado nos propone una extensión performativa entre lo escrito y lo leído. Así, la forma como estas poesías son recibidas es fundamental para una performance de resistencia, pues "la voz viva tiene necesidad - una necesidad vital - de revancha, de "tomar la palabra", como se dice" (ZUMTHOR, 2018, p. 17).

En la poesía de Arjona, el fragor del silencio nos recuerda los innumerables casos de feminicidios, pues "la intención degenerativa del cuerpo y el ser se presenta como 
si fuera un diario informativo: Una ciudad situada en el desierto se ha convertido en un basurero al que es arrojada 'la carne del desierto'" (ROJAS JOO, 2016, p. 57). La barbaridad del silencio nos motiva a continuar la performance, pues en la vivaz voz del silencio hay un triste canto que suplica ser escuchado.

Estas voces "calcificadas" nos remiten al desierto de cuerpos, que son también testimonios de perversidades. Al reforzar una voz sin sonido, Arjona desnuda una sociedad connivente, resaltando que los responsables por estos crímenes deben ser punidos. De esta cruel experiencia, tenemos acceso al coro de fantasmas que ronda el desierto de Juárez, traduciendo lo peor del ser humano: la impunidad de estos asesinatos.

En el segundo texto "Juárez tan lleno de sol y desolado", lanzado originalmente en 2004, observamos que la sensibilidad de Arjona está arraigada en la árida condición del desierto y en la dinámica del narcotráfico de la frontera. Este poema describe la violencia que pudre la sociedad juarense: "La ciudad nos pudre en su violencia/el desierto calienta con sus balas" (2020, p. 39). Se trata de un desierto calentado por el fuego de las armas y por valores morales crueles salpicados por la sangre de las víctimas.

En esta poesía, el desierto es descripto como un patíbulo controlado por demonios: "La ciudad se muere poco a poco/no hay auxilio que llegue a rescatarla/engullida por la bestia y sus demonios/fría y cruel esta cacería humana" (2020, p. 39). También tenemos una voz lírica que aborda cada historia silenciada como una memoria que debe ser recordada, ya que "el cuerpo femenino en las sensibles palabras de Arjona recrea el desierto, la frontera y el cuerpo femenino como entes cuyo destino es la muerte" (AYALA, 2005, p. 110).

Por lo tanto, en la lírica de Arjona, Juárez es un territorio asfixiado por la violencia y descuartizado por la brutalidad de las muertes. Su poesía reconoce la corrupta relación entre dominación masculina y narcotráfico. Esta violencia es retomada por Arjona en su libro de cuentos Delincuentos, de 2005, en el cual “destaca la desigualdad de género con la banalización de los asedios y de los crímenes contra las mujeres", aproximando valores morales de los discursos misóginos en México (GOMES, 2021a, p. 43).

Retomando esta performance activista de Arjona, en el tercer texto seleccionado, "Páramo", diferentes fuerzas políticas se entrecruzan y la violencia contra la mujer es vista como un crimen secundario, sin mucha relevancia. Tal poema sintetiza una década de crímenes ${ }^{3}$. La imagen de un desierto de sangre reabre la discusión en torno a la miserable dádiva de las maquilladoras: la ejecución de sus trabajadoras. Las industrias extranjeras son vistas como parte de los agentes que participaron en los crímenes "ávidas/cómplices/frívolas/tóxicas/mísera/dádiva" (2004, p. 116).

En este texto, el sol cede espacio a las sombras de la pérdida y a las sórdidas relaciones políticas, reconociendo que las maquilladoras son vistas como cómplices del exterminio de mujeres. Estas empresas contaminaron las esperanzas de millones de mujeres y no les dieron condiciones de sobrevivir, por eso "tóxicas" al promover una "dádiva" de más miserias. La voz lírica no deja dudas cuando se refiere a la dádiva maldita de las maquilladoras, pues su connivencia con el sacrificio de mujeres en Juárez no puede esconderse bajo la alfombra. En esta dinámica, el cuerpo femenino ejecutado

3 Este poema forma parte de la antología Juárez tan lleno de sol y desolado, publicado por Chihuahua Arde en 2004. En este artículo, usamos una publicación de la Revista Chicana/Latina Studies de 2004. 
nos remite al triunfo del poder machista, dado que, "para que un sujeto adquiera su estatus masculino, como un título, como un grado, es necesario que otro sujeto no lo tenga" (SEGATO, 2013, p. 24).

También, en el pulso lírico de "Páramo", los envueltos en los crímenes son descriptos como "crápulas", que buscan mantener su status por medio del sacrificio de inocentes. Los vínculos "sórdidos" nos apuntan un sistema criminal que funciona de forma vergonzosa, pues depende de la omisión de los agentes públicos. No eran solo bandidos que mataban a aquellas mujeres, eran hombres interesados en dominar y esparcir el terror de las muertes, provocando un hedor vergonzoso: la condición "fétida" de la degradación de una sociedad.

Este testimonio de Arjona refuerza cuánto la violencia brota de diversas instituciones mexicanas, tanto las oficiales como las clandestinas. Su poesía describe una violeta estructura gestionada por el narcotráfico y por la impunidad, que se sustenta por un "sistema de status" que "se basa en la usurpación o exacción del poder femenino por parte de los hombres" (SEGATO, 2003, p. 144). Arjona es testigo de las tensiones de género a partir de los abusos sexuales impuestos, ya que la víctima pierde el control sobre su cuerpo, cuando este pasa a ser normativizado por las leyes del submundo del crimen: el "control legislador sobre un territorio y sobre el cuerpo del otro como anexo a ese territorio" (SEGATO, 2013 p. 20).

Al tocar el tema del tráfico sexual de mujeres, el poema de Arjona borra las fronteras del tráfico con las investigaciones policiales. Entre el tráfico de drogas y de mujeres, no había diferencia, solo mercaderías. Al exponer "víctimas lánguidas", Arjona nos recuerda cómo estas mujeres eran consideradas de segunda clase por estar asociadas a la prostitución, exponiendo el perverso sistema de abusos, violaciones y mutilaciones. En este caso, el abuso sexual es visto como "un acto intencional del poder y la fuerza con un fin predeterminado, por el cual una o más personas producen daños físicos, mentales o sexuales" (FRAGOSO, 2010, p. 234).

Así, el hacer poético de Arjona se desnuda de palabras para sintetizar lo inexplicable. El uso de esdrújulas refuerza la tonalidad triste de este canto de resistencia. Finalmente, el poema de Arjona cuestiona la impunidad al referirse a un juego de palabras, propio de juegos de nińos, y que es guiado por la continuidad: "cúcara/mácara/ títere/fue". Entre máscaras y fantoches, nadie asume los crímenes. Al apropiarse de una expresión popular relacionada al juego, Arjona traduce la siniestra investigación propia de los interesados en jugar el sucio juego de los feminicidios sin que los culpados fuesen identificados. Para Lagarde, estos crímenes forman parte de las normas patriarcales que violan los derechos humanos, pues "se articulan con otras condiciones sociales y económicas de extrema marginación y exclusión social, jurídica y política" (2005, p. 01).

En esta perspectiva, la performance lírica de Arjona nos invita a leer sus poemas en voz alta, explorando la naturaleza plural de la poesía, que propone un encuentro y confrontación personal, pues esta performance opera de forma dialógica, dado que el cuerpo reacciona a la materialidad del objeto, y a la voz del/la lector/a y se mezcla virtualmente a la voz de la poeta según nos enseña Zumthor (2018, p. 59).

A continuación, pasamos a resaltar las contribuciones de la lírica de Marjorie Agosín para la divulgación de los feminicidios de Juárez. 


\section{LA VOZ DE LAS SACRIFICADAS}

Marjorie Agosín, después de escribir sobre el desaparecimiento de las víctimas de la dictadura de Pinochet, en Lluvia en el desierto (1999), se dedica a dar voz a las silenciadas de Juárez en Secretos en la arena: las mujeres jóvenes de Ciudad Juárez (2006). Esta antología de poemas retoma los enigmáticos casos de crímenes a mujeres que no fueron aclarados durante décadas. Desde este contexto hostil, Agosín produce poesías que denuncian la normativización de violaciones y asesinatos de mujeres anónimas.

En esta obra, Agosín consigue borrar las cuestiones de género con los valores patriarcales, cuando aproxima reglas machistas de las sórdidas violaciones impuestas a las víctimas del desierto y retoma cuestiones de los derechos humanos. Ella describe las condiciones vulnerables de mujeres que luchan para sobrevivir, sin embargo, son engullidas por la sistemática de la violencia de género. Particularmente, su poesía se dirige a "los desposeídos, marginales e invisibles del 'progreso' neoliberal" por medio de "formas poéticas combatiendo el silencio histórico que se les ha impuesto" (LÓPEZ, 2019, p. 154).

En el poema "Les contaré de ellas", Agosín cuestiona la postura de la prensa que tenta relativizar la barbaridad de los crímenes al cuestionar la vida glamorosa de algunas víctimas: "La prensa ama recalcar la vida de las desaparecidas con dinero con apellidos célebres, con rostros de porcelana" (2006, p. 48). Al exponer las técnicas periodísticas de narración de pistas falsas, Arjona denuncia los intereses que hay detrás de los estereotipos, que prevalecieron en el imaginario popular. Más adelante nos hace conscientes de la realidad de las víctimas que "Vienen de lugares extraños de la zona de Chihuahua" (2006, p.48). Al reconocer el origen humilde de las víctimas, Agosín intensifica su misión de entonar sus gritos. Su intención es cuestionar la postura de descalificar a las muertas como prostitutas y fiesteras.

Este hacer poético viene de una tradición que informa y cuestiona las injusticias sociales y la violencia del Estado, dado que su obra "se inscribe dentro del auge del exilio, se destaca por una poética plural o mosaica en la que combina el lirismo y la pasión por la justicia social" (SCHÜRCH, 2013, p. 141).

En "Les contaré de ellas", Agosín refuerza que todos estos crímenes son frutos de la impunidad, de la falta de investigación, de la total falta de respeto por las víctimas, pues "nadie desea conmemorar sus muertes./Las señoritas extraviadas de Juárez/no tienen dinero/mejor no hablar de ellas" (2006, p. 48). Desde esta perspectiva, su poesía opta por describir los conflictos identitarios que son promovidos por la perversidad de un sistema que solo reconoce lo hegemónico sin respetar las diferencias entre "estructuras sociales y trayectorias personales", silenciando a las mujeres consideradas de segunda clase (CONNELL; PEARSE, 2015, p. 112).

En el entrecruzamiento de voces de cada poema de Secretos de la arena, nosotros, como lectores/as, nos encontramos también y nos solidarizamos con las silenciadas. Según Zumthor, esto sucede porque la recepción da oportunidad al desarrollo de la visión privilegiada del/la lector/a por medio de la interacción de lectura, que sucede cuando este sujeto "encuentra la obra; y la encuentra de manera indeciblemente personal" (2018, p. 49).

En el segundo poema que seleccionamos "Noticieros", la violencia estructural impuesta a esas mujeres se torna más visible, al ser contextualizada por una familia 
mexicana que ve el noticiero de crímenes: "anuncia otra muerte/parece que es la misma mujer dice el niño" (2006, p. 82). En este contexto misógino, las mujeres son vistas como extranjeras por los guardianes del machismo. Además, las sutilezas de este poema atestiguan contra normas milenarias que empujan a las mujeres a sus tumbas como afirma el padre: "todas las mujeres esas son iguales" (2006, p. 82).

Por este ángulo, consideramos que Agosín reconoce las reglas de control y punición del cuerpo de la mujer como parte de las reglas sociales de aquella comunidad, pues "los actos de violencia se comportan como una lengua capaz de funcionar eficazmente para los entendidos" (SEGATO, 2013, p. 31). Por lo tanto, la forma como la noticia es recibida por aquella familia refuerza la premisa de que los feminicidios no son practicados por monstruos, sino que por hombres que creen que las mujeres forman parte del territorio de su virilidad.

Este mensaje está relacionado al hecho de que la madre sea descripta como tan cercana a la mujer asesinada del noticiero, reforzando su lugar de no ser. Esta condición está presente cuando el hijo le pregunta a su madre: “¿Por qué matan siempre a la misma mujer?", y nos deparamos con una esposa muda "Y se hace un pozo de silencio" (2006, p.82).

En la acepción de la antropóloga Lia Zonatta Machado, esta normativización de género es naturalizada para ser aceptada como padrón, proporcionando diversos tipos de violencia contra la mujer. Esta opresión no siempre genera conflicto de forma directa, pero está compuesta de valores que aprisionan a las mujeres a los valores patriarcales. Tales valores forman parte de un repertorio de violencia, reglado por el poder masculino de "controlar, supervisar y hacer obedecer a las mujeres, imponiendo así su voluntad, ya sea mediante agresión físico-moral o solo moral" (MACHADO, 2017, p. 42).

Así, el canto de dolor y luto resuenan por las páginas de Secretos de la arena y nos dejan conmovidos y tristes por el tono de un genocidio sistemático. La escena descripta en "Noticieros" desnuda el contexto social de donde parten las mordazas impuestas. La delicada condición de ser mujer en un territorio tan machista está relacionada a la violencia de género estructural. En busca de registrar la mirada atenta de una activista de los derechos humanos, "Agosín utiliza varias perspectivas y voces poéticas para retratar el dolor de la situación y su espacio emotivo pasando del "lugar del no-ser" al "lugar del ser" (LÓPEZ, 2019, p. 151).

Este poema refuerza las sutilezas de género de la sociedad mexicana y aproxima la imagen de la madre a las mujeres asesinadas en el desierto. Todas las mujeres son iguales para el perverso sistema de abusos. Al exponer el juzgamiento del padre y el silencio de la madre ante una víctima más, la lírica de Agosín explicita el aniquilamiento y nos estimula a adentrarnos en los mecanismos morales y políticos que culpan a las mujeres por haber sido asesinadas. Esta culpa debe ser cuestionada siempre por nuestras lecturas, dado que se trata de una segunda ejecución e impone el doble silenciamiento a los feminicidios.

Dando secuencia a nuestra propuesta de recepción, pasamos a entonar el lamento del poema "Tan sólo la muerte", que se adentra en los sentimientos de las ejecutadas. Este poema desenmascara el estado de terror impuesto a las víctimas "Bienvenida entre la mudez/Y el letargo" (2006, p. 56). No se trata solamente de un canto triste, ya que va más allá de los cuerpos que se duermen en el desierto, pulsando palabras de consuelo 
y solidaridad con las víctimas. Este tono de aproximación injerta en los cuerpos de los muertos la condición de ser, pues "plantea diferentes temas y estrategias, con los que intenta rescatar la memoria de las mujeres y su precarización y desaparición" (LÓPEZ, 2019, p. 150).

Específicamente, esta lírica nos remite al sentimiento de sociabilidad, cuando indica que existe la intención que "Apacigua su cuerpo desbandado" (p. 56). Con esta invitación para reconfortar los cuerpos sacrificados, Agosín nos hermana con las víctimas, pues pasamos a oírlas, cuando leemos/declamamos, ya que "la voz poética nos declara esto de manera explícita, nos dice que, pase lo que pase, no estamos solos. Un trasfondo cargado de significados potenciales" (ZUMTHOR, 2014, p.83).

Por esta perspectiva, en "Tan sólo la muerte", la voz lírica expresa el absurdo del silencio en torno de las asesinadas. Cada verso clama por justicia pues nos envuelve en un aire de soledad infinita. Esta soledad refuerza la ausencia de humanidad, rumiando la lamentable impunidad que ha prolongado durante tantos años este clamor de mujeres perseguidas por la muerte, vista como "mensajera del alivio/Repositora de ese cuerpo que no clama" (2006, p. 56). Al reforzar la soledad de las muertes, todavía clamando justicia, Agosín desenmascara las estrategias de disminuirlas y pone de manifiesto el abandono de estas mujeres. En medio del trágico final “Reconoce el espanto/ Se la envuelve toda" (2006, p. 56).

Por tanto, el absurdo de los crímenes es experimentado en este triste tono, apuntando a una sociedad que no cultiva la impunidad. Los narcotraficantes, los políticos, los empresarios, los policías son responsables por la continuidad de esta matanza. De esta forma, el desierto funciona como una de las fronteras de este genocidio, ya que las voces de las asesinadas "actúan como oráculos" del destino de las memorias silenciadas (SCHÜRCH, 2013, p. 150). Por su estética de valorización de los derechos humanos, la lírica de Agosín sustenta un activismo de homenaje y respeto a las víctimas, rescatando el trágico momento de la historia de las mujeres mexicanas.

Para finalizar, proponemos nuestras reflexiones sobre las intersecciones entre la voz de la poeta y la voz de las víctimas de feminicidio.

\section{SOBRE LAS HERENCIAS LIIRICAS}

Al envolvernos en las tristes canciones de Arminé Arjona y Marjorie Agosín, constatamos la relevancia de esta lírica activista. Por lo tanto, sus poesías continúan rescatando las voces de las víctimas todas las veces que leemos sus textos. En el contexto de Juárez, tales performances líricas se experimentan como un doloroso ejercicio de recuerdo, ligadas a un activismo de homenajes.

El dolor de la lectura es parte de la herencia de este triste episodio, cuyas ejecuciones sumarias siguen funcionando como códigos espectrales de una sociedad sexista y misógina. Tales ejecuciones también son abordadas en Argentina y en Brasil. Por ejemplo, en la novela autobiográfica Chicas Muertas (2014), la argentina Selva Amada retoma casos verídicos de feminicidios que no fueron aclarados en su juventud. En la obra Mulheres empilhadas (2019), Patrícia Melo entrelaza los juicios por feminicidio en el estado de Acre, con la historia de una abogada perturbada por el asesinato de su propia madre. 
Así, en la segunda década del siglo XXI, observamos que hay una mayor preocupación por parte de las escritoras en describir el imaginario de este crimen. Con estos ejemplos, podemos decir que la experiencia de la escritura activista continúa resonando por América Latina, siendo explorada como un modelo de resistencia y denuncia de la "lógica de los atenuantes jurídicos", que dan respaldo al modus operandi de este crimen (GOMES, 2021b, p. 163). Para las escritoras, rescatar los feminicidios es resistir contra la lógica misógina, que se perpetua en cada ejecución.

Como ejemplo de esta lógica, retomamos el caso del feminicidio de una de las primeras poetas activistas de Ciudad Juárez: Susana Chávez, que fue asesinada el 3 de enero de 2011 por tres jóvenes delincuentes con los que tenía una relación de asesoramiento. Después de una discusión sobre los crímenes que los jóvenes practicaban, Susana fue brutalmente abusada y silenciada. Infelizmente, un fiscal culpó a Chávez del riesgo que corrió al involucrarse con los delincuentes. La crueldad de este crimen y la responsabilización de la víctima motivaron muchas manifestaciones contra la impunidad en México.

Al hacer homenaje a la amiga en "Susana sólo duerme" ${ }^{4}$ Arjona retoma la lucha de tantas otras escritoras que no omitieron explicitar el feminicidio como una grave epidemia social: "Ni seis manos pudieron contenerte/surge un grito en la voz/del sueño inerme/pues tu canto y palabra remolino/enraizada quedó/Tu voz no duerme" (2011). Incluso después de tantas denuncias y cuestionamientos a la postura de las investigaciones, Susana recibió el mismo final que aquellos por los que luchó. Al trasladar la culpa de la atrocidad sufrida a la víctima, una vez más la policía mexicana refuerza los viejos códigos misóginos de juicio y aniquilación de las víctimas de agresión sexual.

En un homenaje a la trágica muerte de Susana, Arjona refuerza la importancia del activismo lírico para que continuemos luchando por la igualdad de género. Al repetir el grito de Susana, la poesía de Arjona rescata también el llanto de las ejecutadas en el desierto. De esta construcción poética oímos un grito colectivo, confundiendo las fronteras sociales y artísticas de estos sujetos. Tal identificación es posible por el hecho de que la voz sea un elemento fundamental de la "performance", vista aquí como la concretización de una identificación: "de la virtualidad a la actualidad" (ZUMTHOR, 2014, p. 35).

En este poema, Arjona canta la propia poesía de resistencia y exalta la memoria que no calla. La voz que pulsa se proyecta como un homenaje a todas, pues la lírica coadyuva a otras voces silenciadas, pero solidarias entre sí: "Tu palabra voraz lanza su Diana/ Tu palabra veraz nos contamina/Tu palabra vivaz profunda y llana/Tu palabra vital en fuego arremolina" (2011). Esta relación con la guerrera que canta y refuerza cómo la lírica activista puede ser experimentada como una flecha apuntada a los culpables.

Con este activismo, la voz de Arjona se confunde con la de Susana, pues "su violento sacrificio realmente se ha vuelto la sangre de todas las mujeres y de la sociedad" (ROJAS JOO, 2016, p. 50). En este canto de tristeza, tenemos una cariñosa valorización de todas aquellas que luchan contra la epidemia de los feminicidios. Así, al elegir el sonido de la

$4 \quad$ El poema "Susana sólo duerme" fue publicado el 14 de febrero de 2011, un mes después de la ejecución de la activista. Disponible en <https://ardapalabra.wordpress.com/2011/02/28/susana-solo-duerme/>. Accedido el 18 may. 2021. 
poesía de Chávez, Arjona prioriza sus contribuciones a la lucha contra el feminicidio y destaca cuánto la poesía activista vibra porque tiene largas raíces de resistencia.

Finalmente, la intersección entre la voz lírica y la voz de la activista silenciada se hermanan y refuerzan el grado de unión de las mujeres en la lucha por el fin de estos crímenes. Consideramos que la lírica activista de Arjona retoma no solo la voz de la poeta ejecutada, sino que también destaca el papel de las otras activistas. El coro de esas voces líricas forma parte del inventario de los crímenes y se suma a tantos otros documentos como fotos, noticias, reportajes, documentales, novelas, películas, que buscaron desenmascarar el odio que sustentan los siniestros feminicidios de Juárez y, por extensión, de América Latina. 


\section{REFERENCIAS}

Agosín, M. Secretos en la arena: las mujeres jóvenes de Ciudad Juárez. Buffalo, New York: White Pine Press, 2006.

ARJONA, A. Páramo. Chicana/Latina Studies. Latina Research Center of the University of California at Davis. Santo Antonio, Texas, vol. 4, n. 01, pp. 116-117. Disponível em <Www.jstor.org/stable/23014445>. Acesso em 10 jun. 2021.

ARJONA, A. Juárez, tan lleno de sol y desolado. In Montiel, C. U. (org.). Ciudad Juárez em la poesia. Ciudad Juárez: Universidad Autónoma de Ciudad Juárez, 2020.

ARJONA, A. Ardapalabra. Blog produzido entre janeiro e julho de 2011. Disponível em: <https://ardapalabra.wordpress.com/author/ardapalabra/>. Acesso em 10 mai. 2021.

Ayala, S. L. B. Re/presentación en el discurso poético de la frontera, el desierto y el cuerpo feminino (2001-2004). Nóesis. Revista de Ciencias Sociales y Humanidades, vol. 15, núm. 28, pp. 105-127, 2005.

Schürch, T. El desierto de las memorias silenciadas. Revista de Ciencias Sociales, Universidad Arturo Prat, Tarapacá, Chile, n. 30, pp. 140-165, 2013.

CONNELL, R.; PEARSE, R. Gênero: uma perspectiva global. Săo Paulo: nVersos, 2015.

FRAGOSO, J. E. M. et al. (coords.). Violencia contra las mujeres e inseguridad ciudadana en Ciudad Juárez. Tijuana: El Colegio de la Fronteira Norte; México-DF: Miguel Ángel Porrúa, 2010.

GOMES, C. M. A violência estrutural dos feminicídios na literatura latino-americana. Revista Fórum Identidades. Itabaiana, GEPIADDE, vol. 33, n. 01, pp. 31-43, 2021a. Disponível em <https://seer.ufs.br/index.php/forumidentidades/article/view/15493>. Acesso em 05 de jun. 2021.

GOMES, C.M. O corpo feminino como intertexto moral do feminicídio. Revista Fronteiraz, Săo Paulo, PUC-SP, vol. 26, pp. 150-164, 2021b. Disponível em <https://revistas.pucsp.br/ index.php/fronteiraz/article/view/53384>. Acesso em 15 de jul. 2021.

LAGARDE, M. ¿A qué llamamos feminicidio? Primeiro Informe Sustantivo de actividades 14 de abril 2004 al 14 abril 2005. Distrito Federal: Cámara de Diputados, 2005.

López, M. El duelo por el cuerpo ausente en Secrets in the Sand (2006) de Marjorie Agosín. Taller de Letras, Santiago, Pontificia Universidad Católica de Chile, n. 65, pp. 149-154, 2019.

MACHADO, L. M. Violência contra as mulheres: diálogos entre feminismo e ciência social. In: DIAS A. F.; SANTOS E. F.; CRUZ, M. H. S. (orgs.). A transversalidade de gênero na produçâo do conhecimento e nas políticas públicas. Aracaju: Editora IFS, 2017, pp. 37-54.

Rojas Joo, J. A. Género e identidad, elementos en la poesía comprometida de tres poetas chihuahuenses: Arminé Arjona, Susana Chávez y Micaela Solís. Imex revista. n. 9, pp. 47-60, 2016. 
SEGATO. R. L. Las estructuras elementales de la violencia: sobre género entre la antropología, el psicoanálisis y los derechos humanos. Bernal: Universidad Nacional de Quilmes, 2003.

SEGATO. R. L. La escritura en el cuerpo de las mujeres asesinadas en Ciudad Juárez. Buenos Aires: Tinta Limón, 2013.

ZUMTHOR, P. Performance, recepçăo e leitura. Traduçăo de Jerusa Pires Ferreira e Suely Fenerich. Sáo Paulo: Ubu Editora, 2018. 